\title{
FUNGSI GRAMATIKAL DAN SEMANTIS SUFIKS - EUN DALAM BAHASA SUNDA
}

\author{
Yayat Sudaryat \\ FPBS UPI Bandung \\ kisudaryat_sunda@yahoo.com
}

\begin{abstract}
Abstrak: Kajian ini bertujuan mendeskripsikan sufiks -eun dalam bahasa Sunda yang dikaji dari segi fungsi gramatikal dan semantik. Deskripsinya mencakup bentuk kata, fungsi gramatikal dan semantis, perilaku sufiks -eun, fungsi gramatikal sufiks -eun, dan fungsi semantis sufiks -eun. Dalam kajian ini digunakan metode deskriptif. Sumber data kajian ini berupa ragam bahasa Sunda lisan dan tulis. Untuk mengumpulkan data digunakan teknik teks, intuisi atau introspeksi, dan teknik elisitasi. Untuk mengolah data digunakan metode distribusional dengan analisis unsur langsung sebagai teknik dasar, yang diikuti teknik subsitusi sebagai teknik lanjutan. Kajian ini menyimpulkan bahwa sufiks -eun memiliki perilaku mandiri dan gabungan dengan sufiks lain serta reduplikasi. Sufiks - eun membentuk kata turunan dari bentuk dasar. Baik sufiks -eun mandiri maupun gabungan memiliki fungsi inflektif dan fungsi derivatif seperti fungsi verbal, fungsi adjektival, fungsi nominal, dan fungsi numeral. Sebagai akibat hubungannya dengan bentuk dasar, sufiks -eun memiliki makna gramatikal seperti 'orang III ada dalam keadaan BD'.
\end{abstract}

Kata kunci: bentuk kata, kelas kata, sufiks

\section{FUNCTION GRAMMATICALLY AND SEMANTICALLY SUFFIX-EUN IN SUNDANESE}

\begin{abstract}
This study aims to describe the suffix-eun in Sundanese are assessed in terms of grammatical and semantic functions. Includes a description of the form of words, grammatical and semantic functions, behavior-eun suffix, suffix-eun grammatical functions and semantic functions of suffixeun. In this study used a descriptive method. The study of data sources in the form of the language variety spoken and written. Techniques used to collect data text, intuition or introspection, and elicitation techniques. To process the data used distributional methods with direct elemental analysis as the basic techniques, followed by a substitution technique as advanced techniques. The study concluded that the suffix-eun has independent behavioral and combined with other suffixes and reduplication. Suffix-eun forming a derivation of the basic form. Either independently or suffix-eun has combined function and derivative function such inflectional verbal function, the function adjektival, nominal function, and the function of the numerals. As a result to do with the basic form, the suffix-eun has grammatical meanings such as 'third person is in a state of BD'.
\end{abstract}

Keywords: form of words, word classes, suffixes 


\section{PENDAHULUAN}

Kajian terhadap struktur bahasa Sunda (BS) telah banyak dilakukan, baik yang berkaitan dengan subsistem fonologis, subsistem gramatikal (morfologi dan sintaksis), maupun subsistem leksiko-semantis. Ketiga subsistem itu perlu diketahui oleh penutur bahasa agar mampu menggunakan bahasa dengan benar.

Salah satu bagian dari gramatika, yakni bentuk dan pembentukan kata, merupakan objek kajian morfologi. Bentuk kata dibedakan atas bentuk dasar dan bentuk jadian (berimbuhan, ulang, dan majemuk). Bentuk jadian berimbuhan dibentuk dari bentuk dasar dibubuhi dengan imbuhan (afiks). Afiks memiliki fungsi gramatikal dan makna tertentu dalam pembentukan kata. Di samping itu, afiks berkaitan pula dengan kelas kata seperti nomina, verba, adjektiva, dan numeralia.

Kajian imbuhan atau afiks sudah banyak dilakukan, lazimnya dalam kerangka penulisan buku tata bahasa Sunda. Berdasarkan jenis dan posisinya, afiks dibedakan atas prefiks, infiks, sufiks, konfiks, dan afiks gabung.

Tulisan ini bertujuan memaparkan salah satu bentuk sufiks, yakni sufiks -eun. Paparannya mencakup tiga hal, yakni:

a) Perilaku sufiks -eun;

b) Fungsi sufiks -eun; dan

c) Makna gramatikal sufiks -eun.

Dengan bertolak dari pandangan bahwa bahasa Sunda tergolong tipe bahasa aglutinatif, yakni kaya dengan afiks (Robins, 1982), pembentukan kata dalam bahasa Sunda merupakan gejala bahasa yang berstruktur dan bersistem sebagai bagian dari sistem gramatikal suatu bahasa Sunda yang khusus, setidak-tidaknya memiliki perbedaan dengan bahasa lain, khususnya bahasa Indonesia dan bahasa-bahasa Nusantara, umumnya bahasabahasa di dunia.

Rumusan kaidah bahasa yang dipaparkan dalam penelitian ini mempunyai relevansi dengan keilmuan linguistik, terutama bidang morfologi dan semantik. Oleh karena itu, hasil temuan dari penelitian ini diharapkan dapat dimanfaatkan untuk beberapa kegunaan, antara lain, (a) memperkaya khazanah karya gramatika bahasa Sunda; (b) memperluas wawasan bagi peminat gramatika bahasa Sunda; (c) memberikan masukan bagi penulis buku gramatika bahasa Sunda; (d) mendorong tumbuh kembangnya kajian lebih lanjut dalam rangka melengkapi khazanah linguistik Indonesia; dan (e) memberikan informasi kepada peneliti dan pemelajar bahasa Nusantara di dalam rangka mencari keuniversalan dan tipologi bahasa.

Ancangan utama dalam kajian ini adalah teori linguistik struktural secara eklektik yang memandang bahwa unsurunsur bahasa berkorelasi secara sintagmatis maupun paradigmatis untuk membentuk satu kesatuan utuh (the unified whole). Gagasan ini mempengaruhi filsafat gramatika Jespersen (dalam Djajasudarma, 1997:10), yang menyebutkan bahwa segala sesuatu harus diamati bentuk, fungsi, dan maknanya. Pemahaman fungsi dan makna berkaitan dengan hubungan antarunsur dalam membentuk satu kesatuan. Oleh karena itu, beda bentuk harus dicurigai fungsi dan maknanya.

Paradigma linguistik tersebut akan menyangkut bidang kajian ini yang berupa kelas kata dan bentuk kata. Ihwal kelas kata yang menyangkut klasifikasi dan identifikasinya digunakan pandangan Lyons (1981), Givon (1984), Djajasudarma (1993), Quirk et al. (1987), Samsuri (1988), Kridalaksana (1990), O'Grady et al. (1989), dan Alwi et al. (2008).

\section{METODE}

Dalam kajian ini digunakan metode deskriptif. Unsur yang dideskripsikannya adalah unsur bahasa itu sendiri, yakni adverbia statif dan adjektiva yang diwatasinya. Berkaitan dengan metode penelitian dikemukakan data, sumber data, pengumpulan data, dan kajian data.

Data penelitian ini adalah berbagai tuturan dalam bahasa Sunda ragam tulis yang di dalamnya mengandung adjektiva dan adverbia statif. Di samping data tulis, dalam penelitian ini digunakan pula data lisan, yang berupa intuisi kebahasaan peneliti.Hal ini dimungkinkan 
karena peneliti adalah penutur bahasa Indonesia. Data jenis ini disebut data intuitif (Labov, 1972), data replektif atau data introspektif (Botha, 1981). Data intuitif tidak langsung diperlakukan sebagai data penelitian karena harus diuji dahulu keberterimaannya kepada penutur bahasa Sunda lain.

Penentuan ragam tulis sebagai sumber data utama didasari oleh pertimbangan bahwa ragam tulis memperlihatkan ciri yang lebih konsisten daripada ragam lisan, baik dalam hal pemakaian struktur maupun semantik. Dengan perkataan lain, ragam tulis lebih terpelihara daripada ragam lisan sehingga bisa mencerminkan bahasa yang lebih mantap dan baku (Ochs, 1979:51-80). Prosedur ini dibenarkan karena bahasa yang diteliti telah memiliki sistem tulisan (Samsuri, 1988:169).

Untuk keperluan tersebut digunakan ragam bahasa tulis yang berupa buku pelajaran, majalah, surat kabar, dan karya sastra berbahasa Sunda. Penentuan dan pengambilan data seperti itu diharapkan representatif bagi penelitian ini. Selanjutnya, secara acak diambil sejumlah konstruksi yang memiliki bentuk verba berpreposisi untuk dicatat dalam kartu data. Korpus data ini akan dijadikan bahan kajian data (Kibrik, 1977:15) dan diharapkan dapat memenuhi ciri-ciri data yang baik.

Di samping sumber data tertulis digunakan pula sumber data lisan yang berupa intuisi peneliti itu sendiri. Hal ini dibenarkan karena peneliti adalah penutur asli bahasa Sunda. Untuk keberterimaan data intuitif ini, kemudian dicek kepada penutur bahasa Sunda lain secara elisitasi.

Data adverbia statif dalam penelitian ini dikumpulkan melalui tiga teknik, yakni (1) teknik teks, (2) teknik intuisi atau introspeksi, dan (3) teknik elisitasi. Teknik teks dipakai untuk mengumpulkan data verba berpreposisi dari sumber tulis. Teknik intuisi atau introspeksi digunakan karena peneliti sendiri adalah penutur bahasa Sunda yang dapat bertindak sebagai informan dan sekaligus dapat melakukan instrospeksi. Keberterimaan data yang diperoleh melalui teknik introspeksi dicek ulang kepada penutur bahasa Sunda lain melalui teknik elisitasi.

Data yang terkumpul melalui teknik pengumpulan data merupakan korpus yang korelasinya belum jelas sehingga perlu dipilih, dipilah, dan disusun secara sistematis.Data yang telah tertata secara sistematis inilah yang siap dikaji atau dianalisis lebih lanjut.

Kajian data pada penelitian ini menggunakan metode distribusional.Upaya penentu yang digunakan dalam kerangka kerja seperti ini berupa unsur bahasa itu sendiri (Djajasudarma, 1993: 60-61).Unsur bahasa yang dikaji dalam penelitian ini ialah adjektiva, adverbia statif, dan hubungan di antara keduanya. Metode ini dioperasionalkan melalui analisis unsur langsung sebagai teknik dasar, yang diikuti teknik balik (permutasi), teknik sulih (subsitusi), teknik perluas (ekspansi), dan teknik sisip (interupsi) sebagai teknik lanjutan (Sudaryanto, 1993: 3139). Teknik analisis unsur langsung dipakai untuk menentukan unsur-unsur dalam kata. Teknik permutasi dipakai untuk mencermati keketatan hubungan adjektiva dan adverbia statif melalui pemindahan posisinya, apakah urutannya bisa bolak-balik atau tidak.Jika bisa dipermutasi, apakah pengaruhnya terhadap struktur dan makna. Teknik perluas atau ekspansi dipakai untuk melihat potensi adverbiastatif dapat diperluas atau tidaknya dengan unsur lain. Teknik sulih atau subsitusi dipakai untuk melihat kesamaan perilaku adverbia statif dan adverbia atau kelas kata lain dalam frasa.

\section{HASIL DAN PEMBAHASAN}

Kelas kata atau part-of-speech dibedakan atas major class word dan minor class word (Quirk et al., 1987); kelas kata utama dan kelas kata tugas (Alwi dkk., 2008:36), atau kecap lulugu dan kecap pancen (Sudaryat, 2007). Kelas kata utama mencakup (1) nomina, pronomina, numeralia, (2) verba, (3) adjektiva, dan (4) adverbia; sedangkan kelas kata tugas mencakup (1) konjungsi, (2) preposisi, (3) interjeksi, (4) artikula, dan (5) partikel penegas.

Kelas kata utama memiliki makna inheren yang dipandang dari kestatifan dan kedinamisan. 
Dikaitkan dengan kelas kata, nomina dan adjektiva bersifat 'statif' (stative), sedangkan verba dan adverbia bersifat 'dinamis' (dynamic) (Quirk et al., 1987:75). Hubungannya dapat dilihat pada bagan berikut ini.

\section{Bagan 1: \\ MAKNA SITUASI DALAM KELAS KATA}

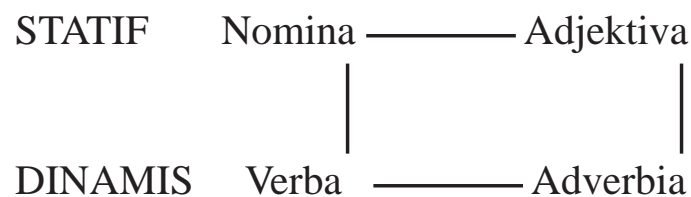

Quirk et al. (1987:74) menjelaskan bahwa nomina disebut statif karena mengacu pada maujud yang stabil ("typically refer to entities that are ragarded as stable, concrete (physical) or abstract (of the mind), sedangkan adjektiva disebut statif karena sebagai atribut yang menjadi ciri stabil dari acuan nomina (as they attribute stable properties to the referent of nouns). Sebaliknya, verba dikatakan dinamis karena mengindikasikan aksi, aktivitas, temporer, atau berubah kondisi (to indicate action, activity, temporary or changing condition), bahkan karena mengimplikasikan kedinamisan verba (to the dynamic implication of the verb), adverbia pun memiliki sifat dinamis.

Situasi statif dan dinamis, menurut Givon (1984:55), berkaitan dengan skala stabilitas waktu (time-stability scale). Nomina memiliki tingkat stabilitas waktu yang paling tinggi (most time-stable), verba memiliki tingkat stabilitas yang paling rendah karena mudah berubah (rapid change), sedangkan adjektiva berada di antara keduanya (intermediate states). Adjektiva menunjukkan keadaan yang kurang stabil jika dibandingkan dengan nomina, tetapi lebih stabil jika dibandingkan dengan verba. Tingkat stabilitas waktu ketiga kelas kata itu tampak pada bagan berikut.

\author{
Bagan 2: \\ STABILITAS WAKTU \\ DALAM KELAS KATA
}

NOUNS ------ ADJECTIVES ------ VERBS

\begin{tabular}{lll}
\hline $\begin{array}{l}\text { most time- } \\
\text { stable states }\end{array}$ & intermediate & $\begin{array}{l}\text { rapid } \\
\text { change }\end{array}$
\end{tabular}

Di samping memiliki kelas, kata juga memiliki bentuk. Bentuk kata adalah wujud kata dilihat dari unsur-unsur morfem yang membentuknya. Bentuk kata dibedakan atas (1) kata asal dan (2) kata jadian (berafiks, berulang, dan majemuk). Kata jadian merupakan bentuk kata yang telah mengalami proses morfologis. Kata berafiks merupakan kata jadian yang mengalami proses pembubuhan afiks, kata berulang merupakan kata jadian yang mengalami proses pengulangan (reduplikasi), dan kata majemuk merupkan kata jadian yang mengalami proses perpaduan leksem (pemajemukan).

Kata berafiks dibentuk melalui pembubuhan beragam afiks. Berdasarkan posisinya dalam kata, terdapat beragam afiks, yakni prefiks (awalan), infiks (sisipan) sufiks (akhiran), konfiks, dan gabungan afiks. Bahasa Sunda termasuk tipe bahasa aglutinatif karena memiliki banyak afiks. Dalam bahasa Sunda terdapat (1) prefiks ba-, di-, $k a-$, $t i-, N-$, pa-, pang-, per-, pi-, sa-, si-ti-, ting-; (2) infiks: -ar-, -al-, -um-, -in-; (3) sufiks: -an, -eun-, -keun, -na, -(n)ing; konfiks: ka-an, kapi-, pa-an, pang-na, pangkeun, pi-eun, pika-, pika-eun, sa-eun, sa-na; dan (5) afiks gabung: di-+-ar-, di-+-an, di-+-ar+ -an, $d i-+-k e u n, d i-+-a r-+-k e u n, d i-+p i-$, di-+pika-, di-+pang-+-keun, di-+pang-+N-+keun, di-+pang-+N-+-ar-+-keun, di-+pang$+N-+-a r-+-a n+-k e u n, \quad N-+-a r-, N-+-a n$, $\mathrm{N}$-+-ar-+-keun, $\mathrm{N}$-+pi-, $\mathrm{N}$-+pika-, $\mathrm{N}$-+pang+ -keun, $\quad k a-+-k e u n, p a-+N-$, pang-+dipika$+-n a$, pang- $+N-+$ pika-+-na, ting-+-ar-.

Dalam penelitian ini dipaparkan tiga hal yang berkaitan dengan fungsi gramatikal dan semantis sufiks -eun, yakni (1) perilaku sufiks -eun, (2) fungsi gramatikal sufiks -eun, dan (3) fungsi semantis sufiks -eun. 


\section{Perilaku Sufiks -eun}

Perilaku sufiks - eun dibedakan atas dua wujud, yakni bentuk sufiks -eun mandiri dan bentuk sufiks -eun berpasangan.

Bentuk sufiks -eun mandiri merupakan sufiks -eun yang membubuhi bentuk dasar secara mandiri tanpa berpasangan atau bervariasi dengan morfem lainnya. Misalnya: bawaeun, beurateun, eraeun, ewateun, gigireun, handapeun, hareupeun, katuhueun, kencaeun, luhureun, tukangeun.

Bentuk sufiks -eun berpasangan adalah sufiks - eun yang berpasangan dengan afiks lain atau reduplikasi. Terdapat beberapa sufiks -eun yang berpasangan, antara lain:

\section{(a)Bentuk pi-eun}

Bentuk pi-eun merupakan sufiks -eun yang berpasangan dengan prefiks

pi-. Misalnya: pigedeun, piimaheun, pipamajikaneun, picontoeun, pigeuliseun, pikarunyaeun.

\section{(b)Bentuk pika-eun}

Bentuk pika-eun merupakan sufiks -eun yang berpasangan dengan prefiks gabungan pika-. Misalnya: pikaseurieun, pikalucueun, pikawatireun, pikagilaeun, pikasebeleun, pikaresepeun.

\section{(c)Bentuk sa-eun}

Bentuk sa-eun merupakan sufiks -eun yang berpasangan dengan prefiks $s a-$. Misalnya: sajungeun, sarebueun, saharitaeun, sakalieun, sapokeun.

\section{(d)Bentuk sa-R-eun}

Bentuk sa-R-eun merupakan sufiks -eun yang berpasangan dengan prefiks $s a$ - dan berbarengan dengan reduplikasi dwimurni. Misalnya: sahos-hoseun, sajung-jungeun, sarebu-rebueun.

\section{(e)Bentuk Rdp-eun}

Bentuk Rdp-eun merupakan sufiks -eun yang berpasangan dengan reduplikasi dwipurwa, yakni pengulangan suku pertama pada bentuk dasar.
Misalnya: lilinieun, jajauehun, rurupaheun, sisidueun, rorombeheun, jeungjeurieheun.

\section{(f) Bentuk Rdm-eun}

Bentuk Rdm-eun merupakan sufiks -eun yang berpasangan dengan reduplikasi dwimurni, yakni pengulangan utuh pada bentuk dasar. Misalnya: arep-arepeun, hiji-hijieun.

\section{(g)Bentuk sa-Rdm-eun}

Bentuk ini merupakan sufiks -eun yang berpasangan dengan prefiks $s a$ - serta berbarengan dengan reduplikasi dwimurni, yakni penguloangan utuh pada bentuk dasar. Misalnya: sahos-hoseun, sajung-jungeun, sarebu-erebueun.

\section{(h)Bentuk lain...Rdm-eun}

Bentuk lain...Rdm-eun merupakan sufiks - eun yang berpasangan dengan reduplikasi dwimurni serta berbarengan dengan kata negasi lain. Misalnya: lain ungkul-ungkuleun, lain bantrak-bantrakeun, lain udag-udageun.

\section{Fungsi Gramatikal Sufiks -eun}

Fungsi gramatikal sufiks berkaitan dengan pembentukan kata dilihat dari segi bentuk dan kelasnya. Fungsi gramatikal yang membentuk satu kelas kata dari kelas kata yang sama disebut fungsi inflektif, sedangkan fungsi gramatikal yang membentuk satu kelas kata dari kelas kata lain disebut fungsi derivatif. Dari hasil kajian data ditemukan beberapa fungsi grramatikal sufiks -eun sebagai berikut.

\section{a. Fungsi Verbal}

Fungsi verbal merupakan fungsi gramatikal yang membentuk verba atau kata kerja, baik dari verba maupun dari kelas kata lain. Fungsi verbal sufiks -eun tampak pada contoh: eraeun, hayangeun, pohoeun, ingeteun, reuwaseun, sieuneun, mangmangeun.

\section{b. Fungsi Adjektival}

Fungsi adjektival merupakan fungsi grramatikal yang membentuk adjektiva atau kata sifat, baik dari adjektiva maupun dari kelas 
kata lain. Fungsi adjektival sufiks -eun tampak pada contoh: beurateun, hampangeun, tiiseun, haneuteun, hareugeueun, kotokeun.

\section{c. Fungsi Nominal}

Fungsi nominal merupakan fungsi grramatikal yang membentuk nomina atau kata benda, baik dari nomina maupun dari kelas kata lain. Fungsi nominal sufiks -eun tampak pada contoh: luhureun, handapeun, hareupeun, tukangeun, gigireun, kencaeun, kauhueun.

\section{d. Fungsi Numeral}

Fungsi numeral merupakan fungsi grramatikal yang membentuk numeralia atau kata bilangan, baik dari numeralia maupun dari kelas kata lain. Fungsi numeral sufiks -eun tampak pada contoh: tilueun, opateun, limaeun.

\section{Fungsi Semantis Sufiks -eun}

Fungsi semantis sufiks -eun mengacu kepada makna gramatikal yang muncul akibat pertemuan sufiks -eun dengan bentuk dasar yang dibubuhinya. Ada dua jenis fungsi semantis sufiks -eun, yakni fungsi semantis sufiks - eun mandiri dan fungsi semantis sufiks -eun gabungan.

\section{Fungsi Semantis Sufiks -eun Mandiri}

Fungsi semantis sufiks -eun mandiri muncul akibat pertemuan sufiks -eun dengan bentuk dasar (BD) yang dibubuhinya. Dari hasil analisis data ditemukan delapan fungsi semantis sufiks -eun mandiri, yakni:

(1) 'Orang III ada dalam keadaan BD': eraeun, keseleun, hampangeun;

(2) 'menjadi merasa BD': atoheun, ngeunaheun, taakeun;

(3) 'hal-hal yang bakal di-BD': dahareun, bawaeun, beulieun;

(4) 'penyakit karena BD': ewateun, leuncangeun, geregeseun;

(5) 'hanya cukup untuk BD': tilueun, opateun, limaeun;

(6) 'dalam keadaan ter-BD': tinggaleun;

(7) 'berada dibagian BD': luhureun, handapeun, hareupeun, tukangeun, gigireun, kencaeun, kauhueun; dan

(8) 'a seperti b': harigu manukeun, tikoro kotokeun, careham hayameun;

\section{Fungsi Semantis Sufiks -eun Gabungan}

Fungsi semantis sufiks -eun gabungan merupakan fungsi semantis sufiks -eun yang bergabungan dengan proses morfologis lain. Dari hasil analisis data ditemukan sebanyak delapan fungsi semantis sufiks -eun gabungan, yakni:

(1) 'bakal menjadi BD': piimaheun, pipamajikaneun, pisalakieun, pigeuliseun, pikasepeun;

(2) 'membuat menjadi BD': pikaseureieun, pikasebeleun, pikagilaeun;

(3) 'hanya untuk BD': sarebueun, sakalieun, sabrakeun;

(4) 'hanya saat untuk BD': sahos-hoseun, sajung-jungeun, sahing-hngeun;

(5) 'dalam keadaan seperti BD': lilinieun, sisidueun, rorombeheun;

(6) 'BD untuk': jajauheun rurumpaheun;

(7) 'menjadi di-BD': arep-arepeun, hii-hijieun, saurang-urangeun; dan

(8) 'bukan untuk di-BD sekai': lain ungkulungkuleun, lain udag-udageun.

\section{SIMPULAN}

Sufiks -eun merupakan salah satu sufiks dalam bahasa Sunda. Sufiks - eun dapat bersifat mandiri atau bergabung dengan sufiks lain dan reduplikasi. Sufiks -eun memiliki perilaku morfologis, fungsi, dan makna gramatikal.

Perilaku sufiks -eun mandiri melekat langsung dengan bentuk asalnya, sedangkan perilaku sufiks -eun gabungan bergabung dengan sufiks lain menghasilkan sufiks pi-eun, pik-eun, sa-eun, sa-R-eun, Rdp-eun, Rdm-eun, sa-Rdm-eun, lain...Rdm-eun.

Fungsi sufiks -eun dapat berupa fungsi inflektif dan fungsi derivatif. Fungsi inflektif sufiks -eun tidak mengubah kelas kata menjadi kelas kata lain, sedangkan fungsi derivatif sufiks - eun mengubah kelas kata menjadi kelas kata yang lain. Fungsi derivatif sufiks -eun adalah 
fungsi verbal, fungsi adjektival, fungsi nominal, dan fungsi numeral.

Makna gramatikal sufiks -eun, baik yang mandiri maupun yang gabungan masing-masing menunjukkan delapan makna gramatikal seperti 'orang III ada dalam keadaan BD' dan 'bakal menjadi BD'.

\section{PUSTAKA RUJUKAN}

Alwi, Hasan et al. 2008. Tata Bahasa Baku Bahasa Indonesia. Jakarta: Balai Pustaka.

Botha, Rudolf P. 1981.The Conduct of Linguistics Inguiry. The Haque: Mouton.

Djajasudarma, T.F. 1993. Metode Linguistik. Bandung: Droste, Flip G. \& John E. Joseph (Ed.) 1991. Linguistics Theory and Grammatical Description. Amsterdam: John Benjamins Pub Co.

Givon, Talmy. 1984. Syntax: A Functional Typological Introduction. Philadelphia: John Benjamins Publishing Company.

Kibrik, A.E. 1977. The Methodology of Field Investigation Linguistics. The Hague: Mouton.

Kridalaksana, Harimurti. 1990. Kelas Kata dalam Bahasa Indonesia. Jakarta: Gramedia.

Labov, William. 1972. "Some Principles of Linguistics Methodology" dalam Language and Society1.1:97-120.
Lyons, John. 1981. Introduction to Theoretical Linguistics. London: Cambridge University Press.

O`Grady, William et al.1989. Contemporary Linguistics. New York: St. Martin`s.

Ochs, Elinor. 1979. "Planned and Unplanned Discourse" in Givon (eds.), Discourse and Syntax. Vol 12. New York: Academic Press.

Quirk, Randolp et al. 1987. AComprehensive Grammar of The English Language. London: Longman.

Robins, R.H. 1982. Sistem dan Struktur Bahasa Sunda. Jakarta: Jembatan.

Samsuri. 1988. Analisis Bahasa. Jakarta: Erlangga.

Sudaryanto. 1993. Metode dan Aneka Teknik Analisis Bahasa. Yogyakarta: Duta Wacana University Press.

Sudaryat, Yayat, dkk. 2007. Tatabasa Sunda Kiwari. Bandung: Yrama Widya.

\section{UCAPAN TERIMA KASIH}

Penulis mengucapkan terima kasih kepada semua pihak yang telah membantu penelitian ini. Juga kepada jurnal Lokabasa saya ucapkan terima kasih atas penerbitan artikel ini. Semoga bermanfaat bagi masyarakat akademik. 